\title{
First-Person Science Inquiry in Virtual Ambient Environments
}

\author{
Tom Moher, Andrew Johnson, and Yongjoo Cho \\ Electronic Visualization Laboratory \\ University of Illinois at Chicago \\ Chicago, IL 60607 USA \\ moher@uic.edu
}

\begin{abstract}
Virtual ambients are a class of restricted simulations designed to support science inquiry learning among elementary school students. Virtual ambients employ large multi-user displays to support "first-person" collaborative exploration, data collection, and the construction of support for hypotheses in simulated environments. In order to reduce the cognitive load on learners, navigation-in space, time, and scale-is used instead of traditional learning simulations' direct control of independent model variables. Early experience with elementary school students at three grade levels is reported, employing a configurable virtual ambient named the Field.
\end{abstract}

\section{Keywords}

Inquiry learning, simulation, educational technology, children, virtual ambients

\section{VIRTUAL AMBIENTS}

Elementary school science is about asking questions, collecting data that bear on those questions, and building support for answers [6]. For the past year, we have been developing instructional interventions which employ virtual ambients [5]—-simulated natural and synthetic environments - as loci for children's scientific exploration. Virtual ambients are three-dimensional "first person" spaces where users navigate in space, scale, and time, implemented on multi-user projective (stereoscopic) displays for use by groups of 2-4 students. Virtual ambients may include simulated scientific instrumentation, and may provide users with "bread crumbs" as navigation and data collection aids.

Virtual ambients may be static or dynamic, but unlike traditional simulations, they offer users no direct control over independent variables. This constraint is designed to reduce the cognitive burden of exploring complex input spaces $[1,2,3]$ by limiting young learners to familiar concepts and activities: moving around, seeing things at different scales, and imagining the past and future. It does not preclude the articulation and investigation of causal hypotheses; it simply shifts the burden from artificially manipulating preconditions to finding instances of varying preconditions in space or time.
Virtual ambients provide young learners access to phenomena which might otherwise be inaccessible, while at the same time allowing educators to scaffold learning by controlling the complexity of the simulated world. We are investigating the hypothesis that working in virtual ambients-planning, navigating, observing, collecting and describing data-facilitates both the learning of both scientific investigation skills and specific math and science content learning.

\section{THE FIELD}

In the Field (Figure 1), students collaboratively explore a large "natural" terrain populated by up to eight different plant types. The Field itself has limited affordances: navigation, the ability to take snapshots automatically posted to a class web page, and the ability to place an unlimited number of (biodegradable) flags in the ground. The Field is divided into regions in two independent ways: by the $3 \times 3$ orthogonal arrangement imposed by the picket fences ("sectors"), and by the differential texture maps (grass, gravel, sand) used on the ground ("terrain").

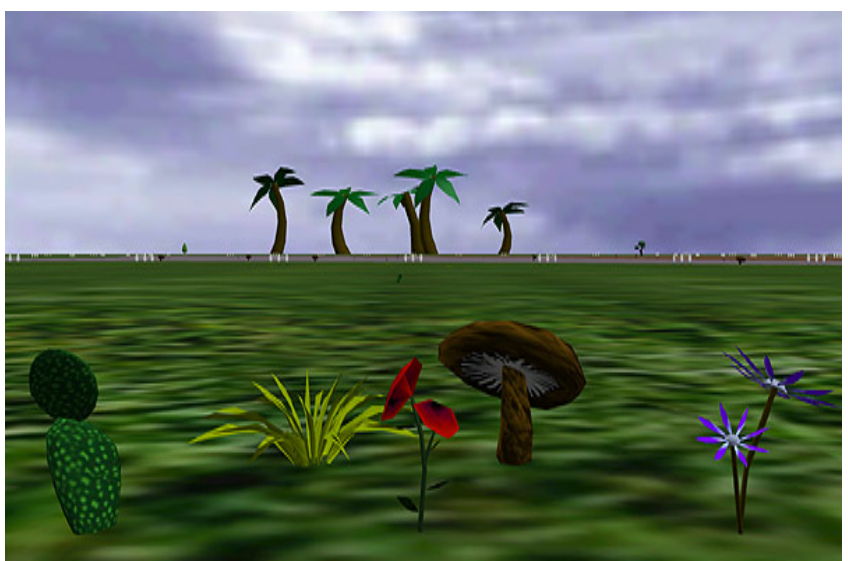

Figure 1. A scene from the Field.

A standalone Java application (Figure 2) allows the Field to be configured by selecting plant types and clicking on the desired locations, supporting learning objectives across a range of grade levels without requiring additional software development.

\section{SIMILARITY AND DIFFERENCE}

An instructional unit designed and tested with second grade students illustrates the use of virtual ambients in a working elementary school context. We configured the Field to contain a few of each of the plant types, scattered around a single sector, and asked the children the simple question: 


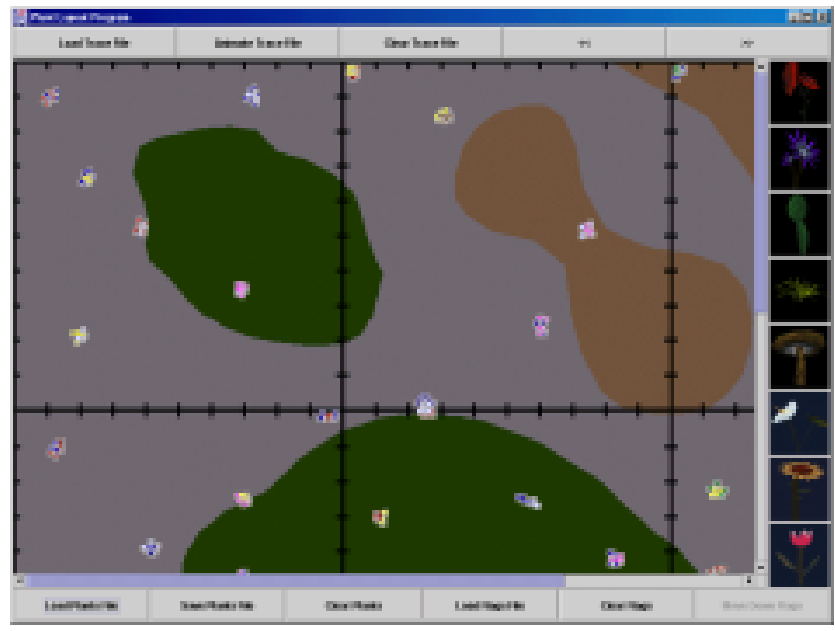

Figure 2. The Field configuration tool.

how many different kinds of plants are there? In a preliminary discussion with the children, the teacher used cut flowers to discuss notions of similarity and difference based on color, size, and shape with the children. He also led a discussion on how they would undertake their data collection, including the need to record data carefully and how to resolve disputes if different observers did not agree on plant similarity or difference.

The teacher organized the students into 8 three-person teams. In turn, each team was "pulled out" and spent 30-45 minutes in the Field. (All eight groups did their exploration on the same school day.) When new plants were encountered, the children drew a picture and wrote a description of their discovery using paper, drawing, and writing tools (crayons and markers),

On the next day, in a whole class setting, each group in turn presented candidate "new plant types," which were accepted or rejected by the class after extended (and often vigorous) discussion of plant features. A montage of their collective drawings is shown in Figure 3.

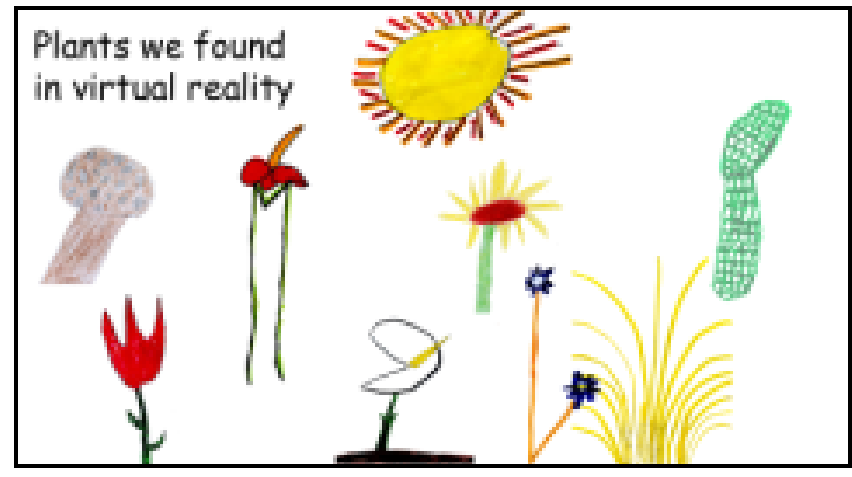

Figure 3. Data collected from the Field.

\section{FLEXIBILITY AND SUSTAINABILITY}

The Field has been used to support learning at several grade levels. For sixth graders [5], we configured the Field to contain clusters of plants each containing 8-10 plants of exactly two different types, and asked students to determine the co-occurrence rules (e.g., plant "buddies"). (An added complexity was introduced, in that the co-occurrence rules were conditioned by sector.) In an upcoming unit, sixth graders will use the field to study sampling and estimation of population distributions.

For fourth grade students, we used a single sector of the Field, and developed multiple configurations to represent the state of that sector across several months. Groups of students visited the Field at simulated one-month intervals and counted the plants, developing frequency distributions conditioned by terrain type. Using these distributions, the students were able to predict plant populations during "missing" months (interpolation), project plant populations into the future (extrapolation), and identify different growth rates (slopes) associated with different terrain types.

In partnership with teachers, we are designing additional virtual ambients providing virtual access to such venues as the Martian surface and polluted streams, as well as expanding our repertoire of Field-based learning units. This year we will also be experimenting with large flat-panel plasma displays, driven by Linux-based PCs, deployed directly in the classroom. While sacrificing potential benefits due to stereoscopy $[4,7]$, this approach is an order of magnitude less expensive than our current configuration, and is based on consumer-driven technologies. Moreover, by obviating human-resource-intensive pullouts, it holds promise as a sustainable model for real schools.

\section{REFERENCES}

1. de Jong, T., van Joolingen, W.R., Swaak, J., Veermans, K., Limbach, R., King, S., \& Gureghian, D., Self-directed learning in simulation-based discovery environments. Journal of Computer Assisted Learning 14, 1998, 235-246.

2. Friedler, Y., Nachmia, R, and Linn, M., Learning scientific reasoning skills in microcomputer-based laboratories. Journal of Research in Science Teaching, 27 (1990), 173-191.

3. Jackson, S., Stratford, S., Krajcik, J., \& Soloway, E. Making dynamic modeling accessible to pre-college science students. Interactive Learning Environments 4(3), 1994, 233-257.

4. Moher, T., Johnson, A., Ohlsson, S., Gillingham, M., Bridging Strategies for VR-Based Learning, in Proceedings of CHI '99 (Pittsburgh, PA, May 1999), ACM Press, 536-543.

5. Moher, T., Johnson, A., Cho, Y., and Lin, Y. Observation-Based Inquiry in a Virtual Ambient Environment, in B. Fishman \& S. O'Connor-Divelbiss (Eds.), Fourth International Conference of the Learning Sciences (Ann Arbor MI, June 2000), Erlbaum, Mahwah NJ, pp. 238-245.

6. National Research Council, National science education standards. Washington DC, 1996.

7. Salzman, M., Dede, C. \& Loftin, R.B., VR's Frames of Reference: A Visualization Technique for Mastering Abstract Multidimensional Information, in Proceedings of CHI '99 (Pittsburgh, PA, May 1999), ACM Press, 489-495. 